\title{
A preparação dos gerentes públicos para o século XXI
}

Revista do

Serviço

Público

Ano 50

Número 2

Abr-Jun 1999

\author{
Kathryn E. Newcomer
}

\section{Introdução}

Uma das várias pressões com as quais os gerentes públicos no mundo inteiro se defrontam estão representadas pelas demandas dos cidadãos, aquelas provenientes do Legislativo - provas de desempenho, enxugamento, contratação de serviço - bem como as demandas por aplicações sempre melhores de uma tecnologia da informação que está em constante modificação. Essas demandas refletem importantes movimentos que vêm se desenvolvendo nos governos de vários países, e é pouco provável a sua redução num futuro previsível.

As expectativas dos gerentes públicos e dos programas por eles gerados mudaram dramaticamente durante as duas últimas décadas do século XX. À medida em que os governos do mundo inteiro passaram a contratar serviços, mudaram as habilidades dos gerentes públicos em termos de negociação e monitoramento.

Este documento discutirá as tendências recentes das expectativas dos governos em relação ao treinamento dos gerentes públicos. Em primeiro lugar, serão examinadas as principais tendências dessas expectativas. Em segundo, identificará as habilidades exigidas dos gerentes públicos para adequar-se a essas tendências, e, em terceiro, oferecerá algumas sugestões quanto aos modos de transmissão dessas habilidades às instituições e pessoas que proporcionam formação e treinamento aos gerentes públicos. Os formadores dos gerentes públicos devem ser responsabilizados (held accountable) pelos seus desempenhos, devendo explorar ao máximo o quanto adequadamente estão preparando-os para os desafios a serem enfrentados no ambiente da administração pública.

Kathryn E.

Newcomer, catedrática de administração pública da George Washington University, Washington, DC; e Ph.D. em ciência política pela University of Iowa

Traduzido por René Loncan 


\section{Demandas que atualmente são colocadas para os governos}

Há quatro tendências-chave nas demandas que os cidadãos e seus representantes eleitos colocam para os governos. Essas tendências têm estado bastante visíveis durante a última década, e mesmo há mais tempo em alguns países. De forma resumida, essas tendências são:

- os gerentes públicos devem proporcionar provas dos resultados de seus programas, o que é conhecido como accountability for performance (responsabilização pelo desempenho);

- o governo deve fazer contratos com entidades privadas ou sem fins lucrativos para a prestação de alguns serviços, o que é conhecido como terceirização ou privatização;

- o governo deve reduzir sua força de trabalho e passar a contratar um maior número de trabalhadores temporários, e portanto menos onerosos, dando-se a esse fato o nome de enxugamento; e,

- deve-se atribuir aos cidadãos, também chamados de clientes, um papel mais importante na tomada de decisões governamentais, envolvendo uma gama de atividades que vai da atribuição de prioridades a objetivos governamentais à definição de regulamentações aplicáveis em empresas privadas.

Os quatro conjuntos de demandas que se colocam para os governos no fim do século XX são significativos, porque provas colhidas no mundo inteiro sugerem que essas demandas são irreversíveis e que continuarão avançando bastante no próximo século. Virtualmente todos os partidos políticos no mundo desenvolvido, dos liberais aos conservadores, estão bastante unidos em suas demandas por accountability, terceirização, enxugamento e foco no cidadão em sua qualidade de cliente. A insatisfação com o envolvimento governamental invasivo em assuntos econômicos e sociais e a existência de déficits crescentes são realidades de abrangência mundial, que têm exercido pressões sobre os governos no sentido de reconsiderar a maneira como conduzem os negócios.

As expectativas que essas demandas colocam para os gerentes públicos são sérias, apresentando aos gerentes, ao mesmo tempo, uma série de perguntas espinhosas que afetam a alocação de recursos. Como observou Franco Archibui, o levantamento dessas expectativas colocam questões sobre como os gerentes públicos deveriam ser preparados para o ambiente em que estarão trabalhando e sobre as habilidades de que necessitarão para desincumbir-se das tarefas que lhes serão atribuídas (1997: 15-6). Formadores e treinadores de gerentes públicos devem analisar essas novas expectativas para identificar como melhorar o seu desempenho e assim ajudar os gerentes públicos a terem sucesso. 


\section{Accountability por desempenho}

A doutrina governamental ao longo das duas últimas décadas tem sido a de tornar o governo (e os gerentes governamentais) accountable (serem responsabilizados) pelo desempenho. Este conceito significa que o desempenho de programas e de políticas públicas serão medidos e que os funcionários, considerados responsáveis pelos resultados mensurados das ações governamentais, serão julgados segundo este critério (Behn, 1997).

Dois aspectos desta formulação merecem mais atenção. Em primeiro lugar, o desempenho não é um objetivo, uma realidade claramente identificável, mas é considerado subjetivamente por algum conjunto de partes interessadas (Newcomer, 1997). E, em segundo lugar, a accountability (responsabilização) também é uma meta em movimento, pois “o ambiente da accountability é uma constelação de forças — jurídicas, políticas, sócio-culturais e econômicas - que exerce pressão sobre as organizações e sobre as pessoas que nelas trabalham, para que se dediquem a certas atividades e deixem de dedicar-se a outras" (Kearns, 1996: 29).

A despeito destas noções fugidias, o debate público em países no mundo inteiro tem-se centrado neste objetivo para fins de atividades governamentais. Nos Estados Unidos, a Lei Sobre Desempenho e Resultados do Governo de 1993 (GPRA) e a Revisão Nacional do Desempenho da administração Clinton (NPR) adotaram este objetivo.

A maioria das conclamações governamentais no sentido da mensuração do desempenho sugerem que os resultados serão utilizados como uma das bases para as decisões sobre alocação de recursos. Por exemplo, no Poder Executivo do governo federal dos Estados Unidos, a Repartição de Gestão e Orçamento (OMB) solicitou que as agências forneçam indicadores de desempenho com suas solicitações orçamentárias dos últimos cinco anos. A OMB sinalizou por meio de muitas de suas iniciativas no sentido de que os indicadores de desempenho devem apoiar as solicitações orçamentárias, e de que os mesmos podem ser utilizados, de maneira defensiva, em exercícios de corte orçamentário.

O Congresso dos Estados Unidos, através da GPRA, legislou no sentido de que, através do planejamento e da mensuração de desempenho, os gerentes deveriam melhorar a confiança do povo norteamericano no governo federal, tornando as agências federais sistematicamente accountable pelos resultados de programas e “... melhorar a eficácia dos programas federais e a accountability pública, por meio da promoção de um novo foco nos resultados, da qualidade dos serviços e da satisfação dos clientes”. A GPRA também acrescenta que a gestão interna deveria ser melhorada através da mensuração do desempenho, mas o foco na accountability, acompanhado de sinais da OMB, indica que a alocação de recursos é o uso primordial, o vetor dos dados sobre desempenho. 
A experiência com a mensuração de desempenho dos programas

públicos em diferentes níveis do governo dos Estados Unidos não tem sido similar. Surgiram algumas histórias de sucesso, mas a realidade de medir-se o resultado de programas com objetivos estatutários amplos e mesmo conflitantes não confere tantas garantias. A mensuração de resultados para objetivos tais como garantir a segurança e a eficácia de medicamentos, embora acelere o processo de aprovação de novos medicamentos, ou a criação de instituições para apoiar a governança democrática e o crescimento econômico em países em desenvolvimento, é certamente difícil. A apreensão por parte de gerentes de programa quanto ao estabelecimento de metas de desempenho, que podem ser difíceis de atingir, não inspira criatividade nesses esforços de planejamento.

\section{A terceirização}

Privatização, contratos externos e terceirização são palavras que estão na moda referindo-se à prática da contratação pelos governos de agentes não-governamentais, para fornecer bens e prestar serviços que eram anteriormente fornecidos e prestados por agências governamentais. Henry Mintzberg, recentemente, interpretou esta tendência como uma conseqüência mundial de que "o capitalismo triunfou” (Mintzberg, 1996: 75). $\mathrm{O}$ pressuposto de que o setor privado pode fornecer melhores bens e prestar melhores serviços tem prevalecido nos Estados Unidos durante a maior parte de sua história, mas Mintzberg assinala que acontecimentos políticos recentes nos Estados Unidos e em outros países têm reforçado este pressuposto.

Em muitos países ocidentais, inclusive nos Estados Unidos, os cidadãos e os políticos têm pedido um governo menor e mais eficiente. Cortar o tamanho das agências governamentais, por meio da contratação de outros agentes, para continuar a prestar os mesmos serviços, tem sido uma técnica popularizada. O termo reinvenção, comum entre os reformadores de governo, baseia-se em uma inovadora forma de prestação de serviços pelo governo, conhecida como terceirização (Osborne e Plastrik, 1997). Também tem sido trazidas à baila, todavia, perguntas a respeito de onde e quando o uso da terceirização é legítimo e desejável (Goodsell, 1993a, 1993b e Moe, 1996).

Mintzberg adverte que a crença em que o capitalismo triunfou está agora desequilibrando as sociedades do Ocidente, através de uma dependência excessiva para com o uso do setor privado para curar todos os males. Ele sustenta que diferentes tipos de organizações são mais adequadas para o fornecimento e a prestação de diferentes tipos de bens e de serviços. Ele receia mudanças indiscriminadas no sentido do uso de 
entidades privadas para fornecer todos os bens e prestar todos os serviços

que o governo fornecia e prestava, e que continuará a fornecer e servir em muitos países. Os gerentes públicos agora estão diante de pressões, no sentido de olhar para o setor privado na busca de ajuda para a prestação de uma variedade de serviços.

\section{O enxugamento}

As demandas em prol da redução do tamanho do governo levaram a diminuições no número de funcionários que trabalham em regime de tempo integral em agências governamentais em muitos países. É evidente a relação entre a terceirização e o enxugamento, pois, se o governo já não está prestando determinados serviços, torna-se necessário uma quantidade menor de pessoal, embora o monitoramento do desempenho dos contratos se torne essencial. O enxugamento tem sido uma ferramenta popular tanto para organizações públicas quanto para organizações privadas nos Estados Unidos, durante as duas últimas décadas.

Nos Estados Unidos, a Revisão do Desempenho Nacional acentuou a necessidade de tornar o governo menor e "mais esperto", sendo que um dos objetivos defendidos, o de reduzir o governo federal em 250.000 cargos, tem recebido grande atenção - especialmente por parte de funcionários federais que se preocupam com a possibilidade de perder seus empregos.

Uma importante distinção, relativa a empregos nos últimos anos, é aquela entre cargos exercidos em regime de tempo integral, com vantagens e cargos exercidos em regime de tempo parcial ou de contrato, sem vantagens. As organizações no setor público e no setor privado devem despender bastante recursos com as funções ou cargos de tempo integral. Com os expressivos aumentos de custo dos benefícios de assistência médica registrados na última década, a atração pelos cargos ou funções de meio expediente ou de tempo parcial aumentou de forma dramática. Por outro lado, o uso desta estratégia para reduzir custos a curto prazo dá lugar também a preocupações de natureza ética, especialmente quanto ao papel do governo na provisão de seguro de saúde para todos os funcionários e/ou para todos os cidadãos.

\section{O papel do cidadão-cliente}

As demandas dos cidadãos e de seus representantes eleitos por um governo reduzido, reinventado e de alto desempenho também têm sido acompanhadas de pedidos de mais contribuição dos cidadãos no 
processo de tomada de decisões. Centrar a atenção no cliente dos serviços tem sido um princípio das técnicas de gestão por qualidade e de gestão pela qualidade total (TQM), bastante populares no setor privado há três décadas. As revoltas e os referendos de contribuintes que têm limitado o tamanho do governo nos Estados norte-americanos e a atenção que a administração Clinton consagra ao assunto, evidenciada pela Revisão Nacional do Desempenho, assinalaram a nova realidade de que os gerentes governamentais não mais ignoram os clientes a seu próprio risco.

As demandas legislativas por planejamento de desempenho e por prestação de contas em todos os níveis de governo nos Estados Unidos realçaram a necessidade de que os cidadãos desempenhem um papel no estabelecimento de prioridades. Os mecanismos para assegurar essa contribuição têm sido inscritos em documentos legais. No nível federal, a GPRA exige a consulta das partes interessadas, à medida em que se desenvolvem os planos estratégicos. O envolvimento dos cidadãos é crucial para as agências federais, na medida em que partes interessadas de todos os níveis de governo trabalham juntas para identificar objetivos de desempenho e metas desejadas de desempenho, conforme exigido por lei. A Casa Branca promulgou, na administração Clinton, o decreto 12.862, em 1993, que exige de forma específica que as agências federais periodicamente façam levantamentos de opinião entre seus clientes, a fim de permitir a operação de um governo mais voltado para os clientes, e as agências obedeceram. Os gerentes de programas federais visivelmente lutam para serem positivamente reativos, indo até os cidadãos e ouvindo-os, por meio da Internet e de encontros face-a-face mais tradicionais, que se realizam em todo o país.

Já há alguns anos, os governos locais nos Estados Unidos têm sido pró-ativos na busca de contribuições de cidadãos em seus esforços de planificação. Em 1995, a força-tarefa para o plano conjunto da Câmara de Vereadores-gerentes, da Associação Internacional de Administrações de Cidades (ICMA), verbalizou expectativas de administrações de governos locais de que os membros da ICMA comprovassem com uma realidade atual a sua conferência anual de 1996, ao notar que:

"No futuro, o governo (local) ver-se-á como um negócio de prestação de serviços, e gastará mais recursos em explicar a seus clientes/donos o que faz e porque o faz. Os gerentes de governos locais darão poderes a seu pessoal e a cidadãos para compartilhar os problemas e as escolhas, porque esta será a maneira mais eficaz de tomar as decisões difíceis sobre que serviços o governo deverá prestar. Levantamentos de opinião sobre atitudes e grupos de foco deverão tornar-se cada vez mais um lugar comum, e a política de marketing há de ser contínua" (Parrish e Frisby, 1997). 
Os governos locais nos Estados Unidos buscam, continuamente, a contribuição de cidadãos através de levantamentos de opinião, reuniões municipais, grupos de foco e a Internet. A satisfação dos clientes tornouse parte integrante dos esforços de mensuração de desempenho (Newcomer, 1997).

A interseção complexa das demandas de governo aqui identificadas são aparentes. Os gerentes públicos estão tentando ser positivamente reativos aos cidadãos e a suas demandas por um governo ainda mais positivamente reativo, menor e "mais esperto". Alguns observadores pressupõem que a mensuração de desempenho, a terceirização e o enxugamento proporcionam oportunidades para melhorar o governo. Quais são as implicações dessas demandas e oportunidades para o conhecimento e as habilidades necessárias aos gerentes públicos neste ambiente turbulento?

\section{Preparar os gerentes públicos para o futuro de maneira eficaz}

Muitas técnicas e estratégias estão disponíveis para serem adotadas por governos para melhorar os serviços. Como se poderia melhor preparar os gerentes públicos para usá-las de maneira eficaz?

Encaminhar os gerentes públicos para escolas de administração de empresas, a fim de aprenderem as técnicas usadas para fornecer melhores bens e prestar melhores serviços no setor privado, não funcionaria. A despeito da semelhança em termos de terminologia, as estratégias e ferramentas populares, tais como gestão por desempenho e contabilidade baseada em custos, não são a mesma coisa no setor privado e no setor público. Adotar, simplesmente, termos semelhantes para realidades diferentes não facilitará nada para ninguém.

De modo semelhante, mandar os gerentes públicos assistir cursos tradicionais em universidades e institutos de treinamento concebidos para gerentes governamentais tampouco funciona. As mudanças nas expectativas do governo andaram mais rápido que as expectativas dos educadores e dos instrutores de treinamento. A realidade do local de trabalho do setor público mudou de maneira muito significativa e muito dos curricula, na sua maioria, não acompanharam essas mudanças.

Os gerentes públicos têm de ser bilíngües, ou seja, fluentes na terminologia usada pelos gerentes do setor privado, pelos especialistas em informática e na linguagem política e governamental utilizada por seus muitos patrões políticos. Em nenhum setor esta necessidade é mais aparente do que no processo orçamentário. Os peritos em modelagem econômica podem ficar perplexos diante do que interpretam como falta de racionalidade no processo de tomada de decisões orçamentárias, mas a racionalidade política das normas e dos costumes é compreensível para 
aqueles que têm a sabedoria contextual adequada. Ao lidar com as partes interessadas nas duas extremidades das transações de terceirização, por exemplo, os gerentes agora necessitam aquele entendimento bilíngüe das expectativas e perguntas muito diferentes que têm a ver com os diferentes conjuntos de clientes, com os quais trabalha o gerente público.

Alguns desses desafios atuais exigem o reaparelhamento tanto dos gerentes públicos quanto dos instrutores que os treinam, e alguns desses desafios exigem uma ênfase mais forte nas bases tradicionais de conhecimento e de habilidades. O Quadro 1 mostra alguns dos conhecimentos e habilidades de especial relevância neste momento.

Aparentemente, as áreas nas quais os gerentes públicos necessitam conhecimentos básicos não são novas. Em vista de questionamentos atuais da legitimidade do governo como prestador de serviços, e das pressões sob as quais os gerentes públicos trabalham atualmente, os conhecimentos de direito e de ética são especialmente relevantes. O comprometimento para com o serviço público não é uma matéria a ser aprendida, mas poderia ser reafirmado por meio do conhecimento da história e dos valores básicos dessa honrada profissão.

Há algumas áreas de desenvolvimento de habilidades que são bastante novas, tais como a mensuração de desempenho e o monitoramento de contratos. As matérias não são novas, mas o aumento recente das exigências em termos de mensuração de desempenho e de terceirização tornaram a proficiência nessas habilidades mais urgente.

\section{Quadro 1: O que os gerentes públicos necessitam conhecer com urgência?}

\begin{tabular}{|l|l|}
\hline Conhecimentos de: & Habilidades em: \\
\hline 1. Direito constitucional & 1. Planejamento estratégico \\
2. Ética & 2. Mensuração de desempenho \\
3. A ética do serviço público & 3. Monitoramento de contratos \\
4. Direito processual em gestão de & 4. Utilização de dados sobre \\
recursos humanos e nas áreas & desempenho e avaliação para \\
substantivas relevantes & melhorar programas \\
5. Procedimentos de políticas de & 5. Prestação de contas sobre \\
alocação de recursos & desempenho e dados \\
6. Instituições governamentais & 6. Administração financeira, inclusive \\
e econômicas & atividades de cálculo de custos \\
7. Direito internacional & 7. Envolvimento dos cidadãos \\
8. Política de grupos de interesse & 8. Solução de conflitos e negociação \\
9. Modelagem econômica & 9. Criação de consenso \\
10. Teoria da liderança e da gestão & 10. Motivação e animação de pessoal \\
& 11. Análise de problemas, inclusive técni- \\
& cas de estatística e de custo-benefício \\
\hline
\end{tabular}


Por exemplo, as diversas demandas por mensuração de desempenho e as ambigüidades inerentes ao processo exigem extenso desenvolvimento de habilidades. A promoção da mensuração de desempenho como ferramenta para avaliar a accountability (responsabilização) gerencial significa ao mesmo tempo que os gerentes devem usar os dados sobre desempenho para demonstrar que o dinheiro alocado a seus programas foi bem gasto e que devem melhorar as operações dos programas que administram. Podem os mesmos dados sobre desempenho ser usados para as duas finalidades?

Coloca-se um dilema significativo ao tentar identificar e coletar dados sobre desempenho para duas utilizações extremamente diferentes. Quando as perguntas têm relação direta com a melhoria da administração de programas, certos dados serão relevantes. No entanto, dados muito diferentes serão relevantes para fins de decisões relativas à questão de se um programa deveria ou não continuar a receber financiamento numa base constante, ou se deveria continuar ou não a receber quaisquer recursos. Os gerentes, pressionados para escolher indicadores de desempenho em épocas de restrições orçamentárias, quando normalmente têm recursos muito limitados para mensuração de desempenho, enfrentam uma escolha difícil. Nestes casos, um dos resultados prováveis é a escolha estratégica de indicadores que façam um programa parecer eficaz diante dos supridores de recursos. Em muitos casos, o tipo de indicador, que pode efetivamente servir de base para decisões voltada à melhoria de um programa, pode proporcionar dados que os gerentes não julguem úteis para fins de alocação de recursos. Diante de uma escolha quanto ao uso de recursos limitados para desenvolver sistemas de mensuração de desempenho, a coleta de dados que venham a apoiar solicitações orçamentárias, provavelmente, há de preponderar sobre a coleta de dados internamente úteis, mas menos capazes de apoiar solicitações de recursos.

Outro dilema interessante que os gerentes públicos enfrentam na atualidade é o de que o uso que se pretende dar aos dados sobre desempenho não está claro. Diante das mensagens de diferentes naturezas, típicas dos pronunciamentos políticos, segundo os quais a mensuração de desempenho deveria ser usada tanto para melhorar os programas quanto o processo orçamentário, pode haver uma falta de clareza quanto ao uso potencial, com relação a conseqüente ansiedade por parte dos gerentes de programa quanto ao que deve ser medido. Os autores políticos dessas solicitações, como membros do Congresso, prefeitos e câmaras de vereadores, podem pedir dados que mostrem ao público o que eles estão realizando, enquanto que gerentes públicos de carreira podem pedir dados úteis para fins internos. Há dois ou mais sinais claros que podem se tornar confusos quando os gerentes intermediários tentam aderir a pressões conflitantes. 
Muitas partes interessadas estão envolvidas na seleção de indicadores de desempenho; elas trazem para a mesa de discussão valores diferentes. Os programas realizados tanto no setor público quanto no setor das entidades sem fins lucrativos têm públicos múltiplos, e normalmente objetivos também múltiplos. Os programas são concebidos para atingir objetivos específicos, tais como melhorar a saúde ou a empregabilidade de seus beneficiários, mas também se espera que sejam prestados de maneira eficiente, eqüitativa, de fácil aceitabilidade por parte dos clientes, ambientalmente sã e justa. Em outras palavras, há muitos valores ligados à prestação de serviços no setor público, e diferentes partes interessadas atribuirão prioridades a esses valores de maneiras diferentes, quando escolherem o que deve ser medido. Não é tarefa fácil, por outro lado, forjar um consenso entre diversas partes interessadas que tenham o poder de escolher o que vai ser medido. As habilidades em termos de estabelecimento de consenso e de solução de controvérsias são, mais do que nunca, necessárias.

A administração financeira é outra área que não é nova, mas que foi muito afetada por recentes pressões que se exercem no ambiente. $\mathrm{O}$ que mudou foi a amplitude e a variedade das habilidades em matéria de administração financeira que são necessárias aos gerentes públicos.

Administrar recursos no governo é hoje em dia talvez mais desafiador que nunca. Agora os gerentes de programa necessitam saber como obter o melhor e mais defensável valor possível pelos recursos públicos dispendidos. A administração de recursos num ambiente de terceirização acarreta arranjos de composição de custos mais complexos do que nunca antes foi necessário. Muitos gerentes públicos necessitam saber como aumentar as receitas para dar apoio a atividades, como por meio de taxas cobradas de usuários que se apliquem a clientes de dentro e de fora de suas agências. Todos os gerentes públicos necessitam ter as habilidades necessárias para evitar o desperdício e o uso não autorizado de recursos, num ambiente em que a tecnologia da informação tornou as transações financeiras mais rápidas, fáceis e vulneráveis do que nunca antes haviam sido.

\section{O treinamento eficaz dos gerentes públicos}

Dadas as muitas áreas do conhecimento e de habilidades aqui identificadas como cruciais para os gerentes públicos, como se poderia prestar treinamento de maneira eficaz? Em primeiro lugar, os gerentes públicos devem entender que seu aprendizado deve ser um processo que dure a 
vida inteira. Nenhum programa acadêmico de um único propósito, numa

única oportunidade, ou nenhuma oficina de treinamento preparará os gerentes públicos para um período muito longo de atividades. A vida útil de cada geração de tecnologia da informação está diminuindo; diminuiu também o tempo de utilidade estática das habilidades que os gerentes públicos aprendem. A educação profissional continuada, e talvez até mesmo a certificação, ao longo de uma carreira gerencial, são necessárias nesta época de mudanças rápidas.

Em segundo lugar, os formadores de gerentes públicos devem ser inovadores, oferecendo tipos de oportunidade de criação de habilidades para gerentes em serviço. A tecnologia da informação hoje em dia facilita essa inovação, na medida em que o apoio de websites, de cd-rom e de tele-conferências pode ser acessível e permite a interação entre os participantes.

Em terceiro lugar, refletindo a necessidade de que os gerentes públicos sejam bilíngües — nas linguagens dos setores privado e público — a instrução para o uso de ferramentas adaptadas para o governo a partir da experiência do setor privado poderia ser oferecida por práticos que tenham a experiência de trabalhar com as técnicas no setor público, em conjunção com formadores profissionais. O ensino em equipe, em que práticos e formadores trabalham juntos, proporciona uma combinação esplêndida de teoria e prática, e coloca na mesma equipe instrutores que tenham familiaridade tanto com a maneira de conduzir negócios do setor público quanto com a do setor privado o que pode ser também muito benéfico.

Em quarto lugar, a prática de envolver gerentes públicos na salade-aula como instrutores pode proporcionar valiosas experiências de aprendizado para os próprios gerentes. Os formadores profissionais deveriam identificar de forma ativa os gerentes públicos eficazes e trazê-los à sala-de-aula para compartilhar suas percepções e experiências com gerentes que ainda não tenham entrado para o serviço efetivo ou que estejam abaixo na escala hierárquica. $\mathrm{O}$ ensino proporciona uma oportunidade única para os gerentes refletirem sobre como podem realizar mudanças significativas e promover um governo eficaz; essas sessões trazem benefícios para todos.

\section{Conclusão}

As demandas que se colocam aos governos, à medida em que nos aproximamos do século XXI, oferecem oportunidades sem precedentes, bem como desafios, aos gerentes públicos. As maneiras tradicionais de conduzir negócios se tornaram obsoletas. A mudança é inevitável, e as opções podem ser enumeradas. Embora os modelos racionais não retratem com exatidão o processo de tomada de decisão em marcha, 
em áreas como a da contratação de serviços e da mensuração do desempenho dos governos, está havendo progresso - dentro dos limites da racionalidade política. Essas questões estão sendo resolvidas politicamente em nações democráticas, como deve ser. Para aconselhar os políticos e a eles responder, os gerentes públicos necessitam treinamento e atenção. Negligenciar as necessidades em termos de aprendizado desse recurso tão valioso poderá prejudicar a todos.

Formadores profissionais e instrutores de treinamento de gerentes públicos carregam a responsabilidade de promover as oportunidades de aprendizado do tipo inovador que são necessárias. É necessário defender essa necessidade, pois governos com bases de recursos estáveis ou mesmo em declínio têm poucas probabilidades de identificar o treinamento gerencial como uma prioridade de base. Os mecanismos para revitalizar os gerentes públicos que não representam custos, tais como o treinamento através da Internet e sistemas que utilizem mentores, podem e devem ser promovidos. O comprometimento para com a melhoria do desempenho do governo acarreta a responsabilidade de romper as idéias fixas e os padrões confortáveis. $\mathrm{O}$ ambiente turbulento da administração pública deveria desafiar as habilidades dos formadores profissionais e instrutores de treinamento de gerentes públicos, de estabelecer parcerias e de marketing para assegurar que os gerentes públicos possam aproveitar as oportunidades, e assim, melhorar tanto a eficácia quanto o comprometimento para com sua profissão.

\section{Referências bibliográficas}

Archibugi, Franco. (1997), "Performance Based Management in Public Administration and Its Training Implications". (Documento de base preparado para o Simpósio Internacional sobre Gestão por Desempenho na Administração Pública, Caserta, Itália, 24 a 26 de setembro).

ARMEY, Dick, Larry Craig, Dan Burton. (1997), "Toward a Smaller, Smarter CommonSense Government / Results Act: It Matters Now”. (Relatório temporário emitido pelo líder da maioria na Câmara dos Deputados Dick Armey, pelo senador Larry Craig, Presidente do Comitê Republicano para Políticas do Senado e, Dan Burton, Presidente do Comitê para a reforma e a supervisão governamentais da Câmara de Deputados. (Setembro).

BarZelay, Michael. (1992), Breaking Through Bureaucracy. Berkeley, Califórnia: University of California Press.

Bern, Robert D. (1997), "What do We Mean By Accountability, Anyway?". (Documento apresentado na Conferência Anual de Primavera da Academia Nacional e Administração Pública, Durham, Carolina do Norte, 7 de junho). 

Avoiding Success Becoming Failure”. The Public Administration Review, v. 55, n. 3 (maio-junho).

Goodsell, Charles T. (1993a.), “Did NPR Reinvent Government Reform?” The Public Manager, v. 22, n. 3 (outono).

Goodsell, Charles T. (1993b.), "Reinvent Government or Rediscover It". The Public Administration Review, v. 53, n. 1 (janeiro-fevereiro).

Hide, A. C. (1997), “Rethinking The Roles Of Public Managers” The Public Manager, v. 26, n. 1 (primavera).

JACQUES, Elliott. (1989), “Requisit Organisation: The CEO's Guide to Creative Structure and Leadership”. Nova York: Cason Hall and Co.

Johnson, Pamela R. e Jordan Stern. (1995), “From Good Enough to the Best in Business: Benchmarking for Public Managers”. The Public Manager, v. 24, n. 3 (outono).

KEARns, Kevin P. (1994), "The Strategic Management of Accountability in Nonprofit Organisations: An Analytical Framework”. The Public Administration Review, v. 54, n. 2 (março-abril).

Kearns, Kevin P. (1996), “Managing For Accountability”. São Francisco: Jossey-Bass Publishers.

KetTL, Donald F. (1996), "Implementation of the Government Performance and Results Act of 1993”. (Depoimento diante de uma audiência conjunta do comitê sobre Reforma e Supervisão Governamentais, Câmara dos Deputados dos Estados Unidos e o Comitê sobre Assuntos Governamentais, Senado dos Estados Unidos 6 de março).

KetTl, Donald F., Patricia W. Ingraham, Ronald P. Sanders e Constance Horner. (1996), "Civil Service Reform: Building a Government that Works". Washington, D.C. Brookings Institution Press.

MintzBERG, Henry. (1996), "Managing Government/Governing Management”, Harvard Business Review (maio-junho).

Moe, Ronald C. (1996), "The Importance of Public Law: Public Law, Private Law and Government Management", Chester Newland e Phillip Cooper, editores, Handbook of Public Law and Administration. São Francisco: Jossey-Bass Publishers.

National Academy of Public Administration. (1997), Effectively Implementing the Government Performance and Results Act. (Relatório do painel sobre a melhora o desempenho do governo da Academia Nacional de Administração Pública). Washington, D.C.: National Academy of Public Administration.

Newcomer, Kathryn E. (1997), “Using Performance Measurement to Improve Public and Nonprofit Programmes”. São Francisco: Jossey-Bass Publishers.

Osborne, David e Peter Plastrick. (1997), “Banishing Bureaucracy: The Five Strategies for Reinventing Government”. Nova York: Addison-Wesley Company Inc.

PARrish, Catherine Tuck e Michele Frisby. (1997), "The Changing Role of the Manager: Developing Skills for the Future”. Public Management, v. 79, n. 9 (setembro).

SAnders, Ronald P. (1997), “The Future Isn't What It Used To Be”, The Public Manager, v. 26, n. 1 (primavera).

SмIтн, Sharon L. e Ronald J. Stupak. (1994), “Beyond Survival: Decision Making for the 1999”. The Public Manager, v. 23, n. 4 (inverno).

STUPAK, Ronald J. (1990), “The language of Strategic Implementation: there is nothing more practical than a good theory". The Practicing Manager, v. 10.

U.S. General Accounting Office. (1997), The Government Performance and Results Act: 1997 Governmentwide Implementation Will be Uneven. (GAO/GGD-97-109) Washington, D.C.: The U.S. General Accounting Office.

Kathryn E.

Newcomer, catedrática de administração pública da George

Washington

University,

Washington, DC; e Ph.D. em ciência política pela University of Iowa 
Resumen

Abstract

\section{A preparação dos gerentes públicos para o século XXI \\ Kathyryn E. Newcomer}

Neste artigo, a autora trata sobre como deve ser feito o treinamento dos gerentes públicos diante de mudanças inevitáveis que vêm ocorrendo no funcionamento das máquinas públicas governamentais em vários países.

As novas demandas, que hoje se colocam aos gerentes públicos, se apresentam como verdadeiros desafios, devendo então os mesmos serem treinados e sempre aperfeiçoados, no que diz respeito, sobretudo, ao atendimento do cidadão-cliente. Este treinamento deverá ser feito de forma eficaz e dinâmica, proporcionando aos gerentes públicos uma valiosa experiência de aprendizado.

\section{La preparación de los gerentes públicos para el siglo XXI}

\section{Kathryn E. Newcomer}

En este artículo, la autora explica como se debe hacer la capacitación de los gerentes públicos, ante los cambios inevitables que vienen ocurriendo en el funcionamiento de las máquinas públicas gubernamentales en varios países.

Las nuevas demandas que hoy día se plantean para los gerentes públicos se presentan como verdaderos desafíos, y aquellos deben, entonces, ser capacitados y siempre perfeccionados en lo que atañe a la atención al ciudadano cliente. Esa capacitación deberá ser llevada a cabo de manera eficaz y dinámica, dándoles a los gerentes públicos una valiosa experiencia de aprendizaje.

\section{The preparation of public managers for the Twenty-first Century}

\section{Kathryn E. Newcomer}

In this article, the author deals on how training of public managers ought to be made, in view of inevitable changes that are taking place in the way public governmental machinery works in several countries.

The new demands that are faced nowadays by public managers appear as real challenges, those managers must, therefore, be constantly trained and upgraded in what regards the delivery of services to customer citizens. This training ought to be made in a dynamic and effective manner, granting public managers a valuable learning experience. 